\title{
A High Power Factor Rectifier Based on Buck Converter Operating in Discontinuous Inductor Current Mode*
}

\author{
Jianbo Yang ${ }^{1}$, Weiping Zhang ${ }^{2}$, Faris Al-Naemi ${ }^{1}$, Xiaoping Chen ${ }^{2}$ \\ ${ }^{1}$ Materials and Engineering Research Institute (MERI), Sheffield Hallam University (SHU), Sheffield, UK \\ ${ }^{2}$ Lab of Green Power \& Energy System (GPES), North China University of Technology (NCUT), Beijing, China \\ Email: jumbo-yang@hotmail.com
}

Received September, 2012

\begin{abstract}
By adding a suitable LC filter to the input of a Buck converter, a high-power-factor buck converter is proposed. The converter can operate in the discontinuous-output-current mode operation. A Buck converter in this operation mode features simple control as the constant duty cycle PWM used. The operation condition of the converter is studied. The validity of analysis is verified by Simulation and Experimental results.
\end{abstract}

Keywords: Discontinuous-output-current; Buck Converter; Power Factor Correction

\section{Introduction}

Intensive research has been carried out to improve the power factor of AC/DC converters [1]-[4]. Among the research, it has been reported that by adding a suitable LC filter to the input of a Buck converter to make the converter operate as power factor correction circuit [5] [6]. An example of the converter is presented in Fig. 1. The input capacitor $\mathrm{C}_{1}$ usually has a low enough value and the voltage across it can be discontinuous. Then a high-power-factor can be obtained by a simple constant duty ratio PWM control. However, the voltage stress across switch(S in Figure 1) and diode (D in Figure 1) imposes major restrictions as the peak value of $\mathrm{Vc}_{1}$ is very high when $\mathrm{Vc}_{1}$ becomes zero for part of the switching cycle. In this paper, the Buck converter with LC input filter operates in a "discontinuous-output-current" mode. The current of output inductor $\left(\mathrm{L}_{2}\right.$ in Figure 1) fells to zero for part of the switching cycle and the voltage of the input capacitor $\left(\mathrm{C}_{1}\right)$ becomes continuous. Thus, the peak value of $\mathrm{Vc}_{1}$ is reduced substantially and switch voltage stress will be no longer a restriction. Besides the reverse recovery loss of the freewheeling diode (D) is reduced.

The goal of this paper is to give a more comprehensive analysis of Buck converter with the LC input filter operating in DICM. In section 2 of this paper, the principle of DICM is analyzed. Based on the analysis, the characteristics of the converter and the conditions for power factor

*Project supported by Natural Science foundation of China (N0. 51277004). The Importation and Development of High-Caliber Talents Project of Beijing Municipal Institutions (No.IDHT20130501) correction are studied in section 3. In section 4, the simulation and experimental verifications are given.

\section{Operation Principles of DICM}

\subsection{Operation with Constant Input}

As shown in Figure 1, if $C_{1}$ has large enough value, it will operate in CCVM and the voltage across $\mathrm{C} 1$ can be considered constant during one switching cycle. $\mathrm{L}_{1}$ has large value so that the input current $I_{i}$ can be considered as constant. Inductor $\mathrm{L}_{2}$ has low enough value and operates in DICM. With these assumptions, the converter is the same as the Buck DC/DC converter operating in DCM and the characteristic waveform are presented in Figure 2. The operation over one switch cycle is as follows:

1) $0<\mathrm{t}<$ DTs: at $t=0, S$ is turned on. The current through $\mathrm{C} 1$ is $I_{i}-I_{o} . \mathrm{L}_{2}$ is charging under constant voltage $\left(V_{i}-V_{o}\right)$. The current through $\mathrm{L}_{2}$ increases linearly from zero. Accordingly, the current through $C_{1}$ decreases linearly. When $I_{2}<I_{i}, i_{c 1}$ is positive, $C_{1}$ is charging. And when $I_{2}>I_{i} \quad i_{c 1}$ is turned to negative, $\mathrm{C}_{1}$ is discharging.

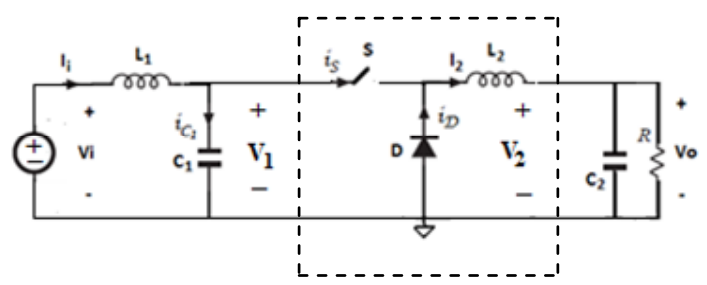

Figure 1. Buck AC/DC converter with LC input filter. 


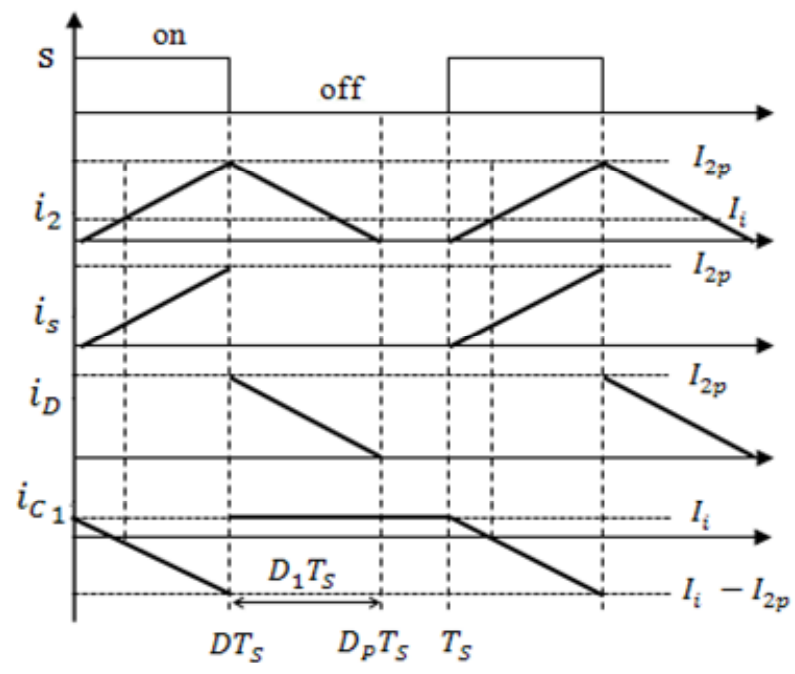

Figure 2. Waveforms for buck converter in DICM.

2) DTs $<t<$ DpTs: at $t=\mathrm{DTs}$, S is turned off. D starts to conduct. $\mathrm{L}_{2}$ is discharging under output voltage. The current through $\mathrm{L}_{2}$ decreases to zero. $\mathrm{C}_{1}$ is charging with input current.

3) DpTs $<t<$ Ts: the current through $\mathrm{L}_{2}$ maintains zero. The output is supported by $\mathrm{C}_{2} . \mathrm{C}_{1}$ is still charging by the input current.

The average voltage across inductor $\mathrm{L}_{1}$, over one switch cycle, is zero in stationary state. Therefore, the average voltage across capacitor $C_{1}$ is equal to the input voltage. As $\mathrm{C}_{1}$ is large enough the changes of voltage across it during a switch cycle can be disregarded. Thus, the instantaneous voltage across $C_{1}$ can be considered the same as the average voltage across it. As a result, the voltage across $\mathrm{C}_{1}$ is the input voltage.

Based on the analysis above, the maximum current through $\mathrm{L}_{2}$ is,

$$
I_{2 P}=\frac{\left(V_{i}-V_{o}\right) D T_{s}}{L_{2}}
$$

The average current through capacitor $\mathrm{C}_{1}$, over one switching cycle, is zero in steady state. The input current equals to the average switch current $I_{s}$ over one switch cycle.

$$
I_{i}=\frac{I_{2 p}}{2} D
$$

Substitution of (1) into (2) gives

$$
I_{i}=\frac{\left(V_{i}-V_{o}\right) D^{2} T_{s}}{2 L_{2}}
$$

The conversion ratio can be defined as $k=\frac{V_{o}}{V_{i}}$

Then an equivalent input resistance $R_{i}$ as the ratio between input voltage and input current is obtained,

$$
R_{i}=\frac{2 L_{2}}{(1-k) D^{2} T_{s}}
$$

The equivalent input resistance $R_{i}$ is proportional to $\mathrm{L}_{2}$ and inversely proportional to switching cycle Ts and duty ratio $\mathrm{D}$.

\subsection{Operation with Sinusoid Input}

The input voltage of the off-line Buck AC/DC converter is a rectified sinusoid voltage.

$$
v_{i}(t)=V_{p}\left|\sin w_{i} t\right|
$$

where $w_{i}=2 \pi / T_{i}$ and $T_{i}$ is the input cycle.

The switching cycle $T_{s}$ is usually much smaller than the input cycle $T_{i}$. Thus, the input voltage can be considered constant over one switching cycle. Thus, the analysis of the converter with rectified sinusoid input over one switching cycle is the same as the converter with constant input. Simply substitution of (5) into (3), the input current is then

$$
i_{i}(t)=\frac{\left(V_{p}\left|\sin w_{i} t\right|-V_{o}\right) D^{2} T_{s}}{2 L_{2}}
$$

If $V_{p}\left|\sin w_{i} t\right| \gg V_{o}$, the input current can be simplified as,

$$
i_{i}(t)=\frac{V_{p}\left|\sin w_{i} t\right| D^{2} T_{s}}{2 L_{2}}
$$

Thus, the input current is proportional to the input voltage when the duty ratio is constant.

Buck converter operates only when the input voltage is higher than the output voltage. Therefore, (6) is valid only for $V_{i}\left|\sin w_{i} t\right|>V_{o}$ When the input rectified voltage equals to the output voltage,

$$
t_{1}=\frac{1}{w_{i}} \arcsin \frac{V_{o}}{V_{i}}=\frac{1}{w_{i}} \arcsin \alpha
$$

$\alpha=\frac{V_{o}}{V_{p}}$. Thus, over half input line cycle, operation is possible only for $t \in\left(t_{1}, \frac{T_{i}}{2}-t_{1}\right)$ as shown in Figure 3. As

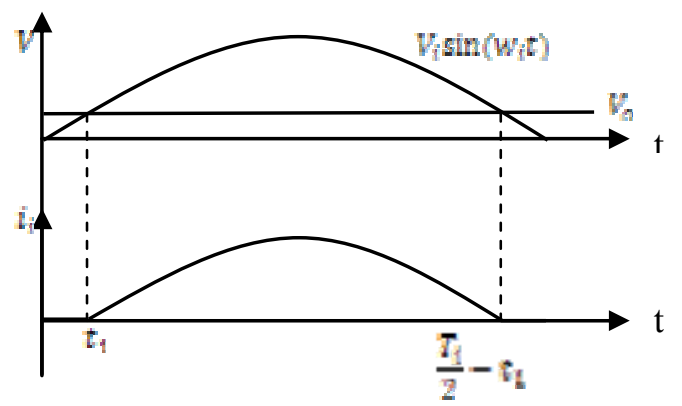

Figure 3. Operation waveforms during half input cycle. 
shown in Figure 3, the input current is zero outside the Interval $\left(t_{1}, \frac{T_{i}}{2}-t_{1}\right)$. This introduces the crossover distortion in the input current. However, the distortion can be accepted if the output voltage is much lower than the peak input voltage.

\section{DICM Operation Boundary}

The average voltage across inductor $\mathrm{L}_{2}$ is zero over a switching cycle in steady state. Thus, according to Figure 2,

$$
\left(V_{i}-V_{o}\right) D=V_{o}\left(D_{p}-D\right)
$$

Then the conversion ratio can be obtained as,

$$
\frac{V_{o}}{V_{i}}=\frac{D}{D_{p}}
$$

As depicted in Figure 2, for Buck converter under DICM $D_{p}<1$. Thus $\left(V_{o} / V_{i}\right)>D$. The conversion ratio has to be larger than duty cycle $\mathrm{D}$ to maintain the converter operates under DICM. This restriction is also valid for rectified input voltage. Therefore, with rectified input voltage, the conversion ratio is,

$$
\frac{V_{o}}{V_{p}\left|\sin w_{i} t\right|}>D
$$

Then,

$$
\left|\sin w_{i} t\right|<\frac{\alpha}{D}
$$

As the maximum value of sinusoid waveform is 1 , $\alpha / D$ must be larger than 1 to maintain the converter operates under DICM. When $\alpha / D$ smaller than 1 , thus for

$$
t \in\left(t_{2}, \frac{T_{i}}{2}-t_{2}\right)
$$

where,

$$
t_{2}=\frac{1}{w_{i}} \arcsin \frac{\alpha}{D}
$$

the converter operates in DCVM [6].

A summarization can be given So far for the operation of the converter. The converter will operate in DICM during the entire input cycle (half-line cycle) when $\alpha / D>1$.

If $\alpha / D<1$, the converter will operate in DCVM for $t \in\left(t_{2}, \frac{T_{i}}{2}-t_{2}\right)$ where $t_{2}>t_{1} t_{1}$ is given by (8). During the intervals $\left(t_{1}, t_{2}\right) \cup\left(\frac{T_{i}}{2}-t_{2}, \frac{T_{i}}{2}-t_{1}\right)$, the converter operates in DICM. Thus, when $\alpha / D<1$, the operation of the converter switches between DICM and DCVM. These intervals are presented in Figure 4.

The conversion ratio $\alpha$ can be obtained as a function of duty ratio $D$ from the energy balance over half input cycle. The input energy can be calculated as,

$$
W_{i}=\int_{t_{1}}^{\frac{T_{2}}{2}-t_{1}} v_{i} i_{i} d t
$$

Substitution of (5), (6), (8) into (15), the input energy is obtained as,

$$
W_{i}=\frac{V_{i}^{2} D^{2} T_{i} T_{s}}{8 L_{2}}\left(1-\frac{2}{\pi} \arcsin \alpha-\frac{2 \alpha \sqrt{1-\alpha^{2}}}{\pi}\right)
$$

The output energy over half input cycle is

$$
W_{o}=\frac{T_{i}}{2} \frac{V_{o}^{2}}{R}
$$

$\mathrm{R}$ is load in Figure 1. With consideration of efficiency $\eta$, the energy balance is,

$$
W_{o}=\eta W_{i}
$$

Substitution of (16) and (17) into (18), a quadratic equation of $\alpha$ can be obtained as,

$$
\alpha^{2} \frac{2 k_{1}}{D^{2}}-\eta\left(1-\frac{2}{\pi} \arcsin \alpha-\frac{2 \alpha \sqrt{1-\alpha^{2}}}{\pi}\right)=0
$$

where $k_{1}=\frac{2 L_{2}}{R T_{s}}$.

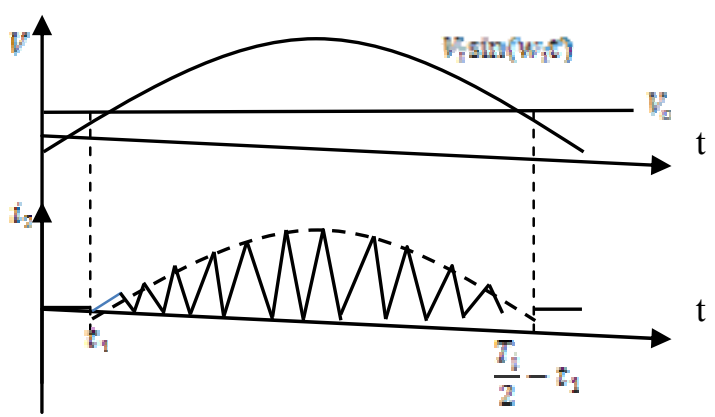

(a) $\alpha / D>1$, DICM

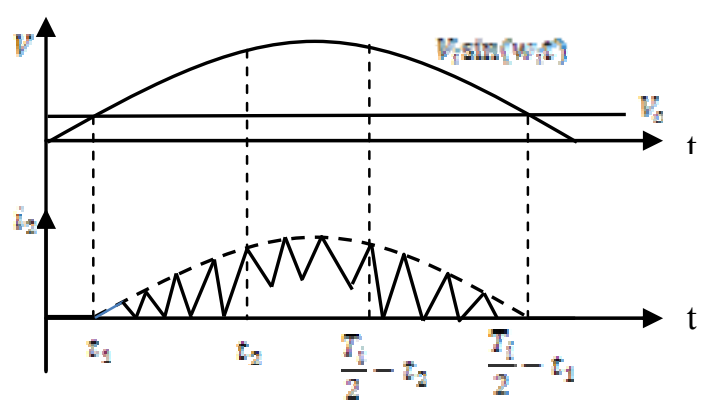

(b) $\alpha / D<1$, switching between DICM and DCVM

Figure 4. Operation modes with different $\alpha / D$. 
Matlab can be used to solve (19) and to plot the conversion ratio $\alpha$ as a function of duty ratio $\mathrm{D}$ with different parameters $k_{1}$. The plot is depicted in Figure 5. The efficiency $\eta$ is assumed to be 0.8 . The results in Figure 5 show the boundary $\alpha / D=1$. When the parts of the curves lie in the area above the boundary, it means $\alpha / D<1$ and the converter operates in DICM. When the remainders of the curves are under the boundary, it means that the converter operates between DICM and DCVM. When $\mathrm{k}_{1}$ is smaller, the more parts of the curves are above the boundary. As $\mathrm{k}_{1}$ is proportional to the $\mathrm{L}_{2}$, it is in accordance with our sense that the smaller $\mathrm{L}_{2}$ operates in DCM more possibly with constant duty cycle.

\section{Results}

\subsection{Simulations}

Simulations were carried out by Psim to verify the discontinuous inductor current operation of the circuit. The components used are: $\mathrm{L} 1=500 \mathrm{u}, \mathrm{L} 2=20 \mathrm{u}, \mathrm{C} 1=220 \mathrm{n}$, $\mathrm{C} 2=2000 \mathrm{u} \mathrm{D}=0.1, \mathrm{R}=13$. The input voltage is
$220 \mathrm{VAC}$ and the output voltage is $36 \mathrm{~V}$. According to the parameters, $\alpha / D>1$. The converter will operate in DICM during the entire half-line cycle base on the analysis in section 3 . The simulation results verify the theoretical analysis and show that input current will follow the input voltage automatically when Buck converter with an input LC filter operates in DICM with a constant the duty cycle.

\subsection{Experiments}

An experiment circuit was also built and the parameters and the components used is the same as the simulations. The control chip was UC3854AN. The experimental results are in accordance with the simulations. The input power is $125 \mathrm{w}$ and the output power is $100 \mathrm{w}$. The efficiency is about $80 \%$. The power factor is 0.98 .

Figures 6 to $\mathbf{1 5}$ verify the boundary condition of the converter operating in DICM. The experiments also prove that the duty cycle $\mathrm{D}$ can be a simple constant value to gain a high power factor when the converter operating in DICM.

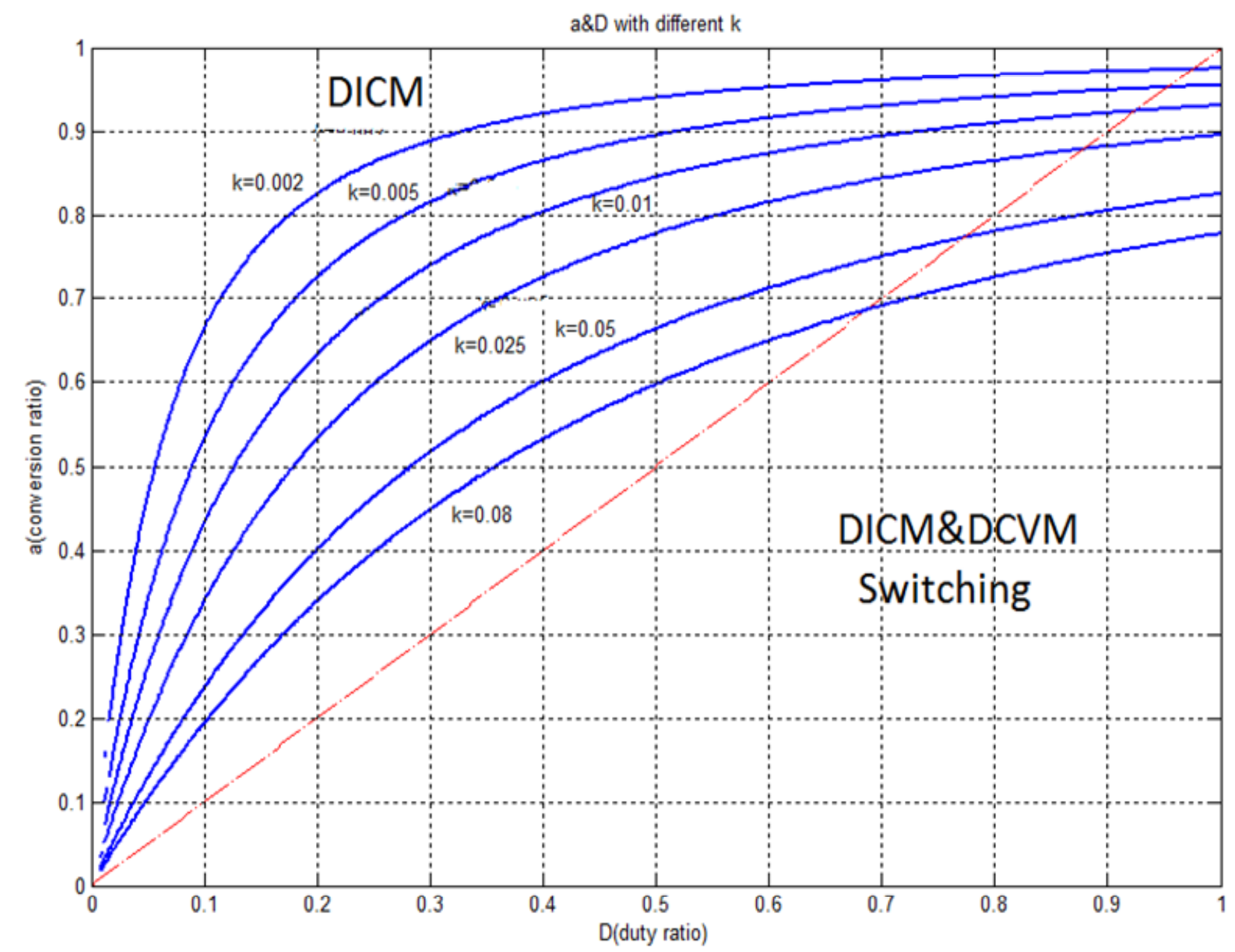

Figure 5. Conversion ratio $\alpha$ with different duty ratio $D$ and $k_{1}$ from (19). 


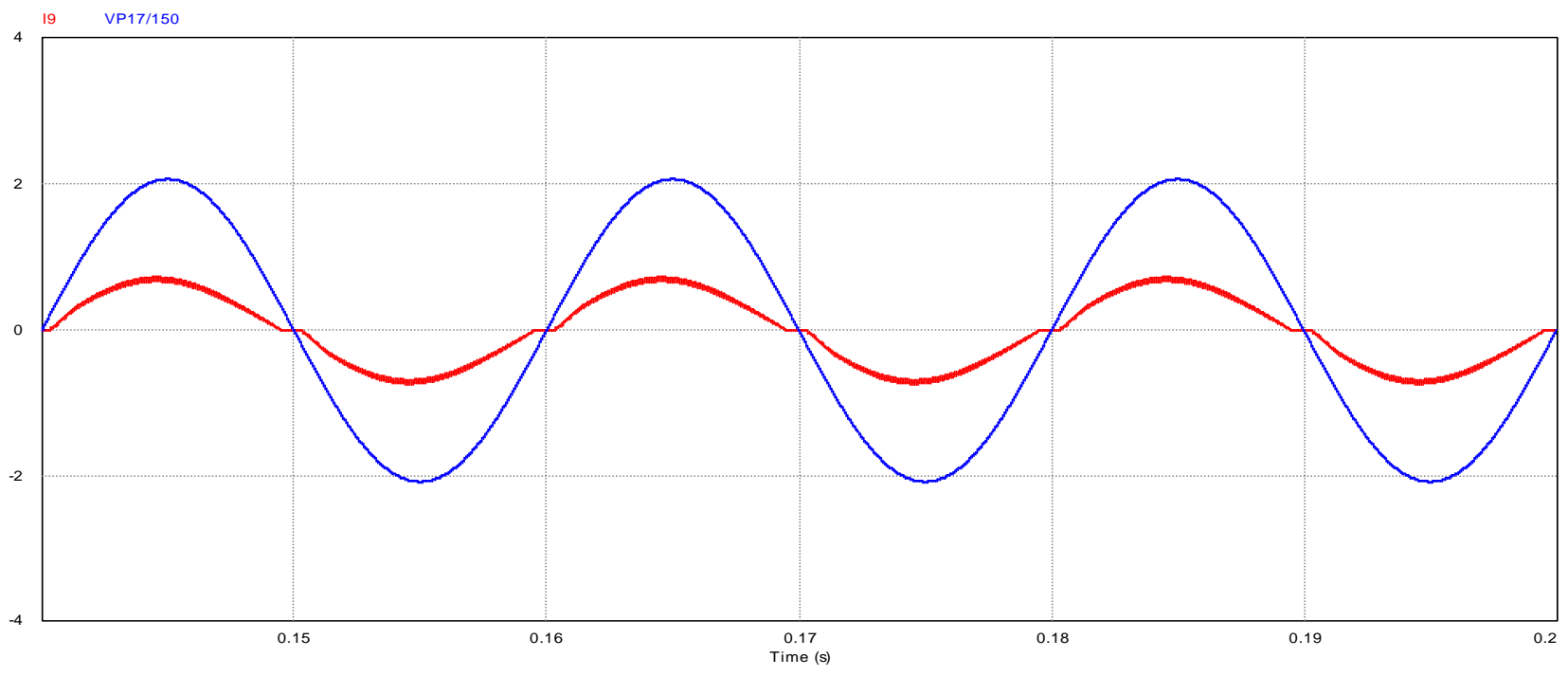

Figure 6. Input voltage and input current (220Vac; 0.52A).

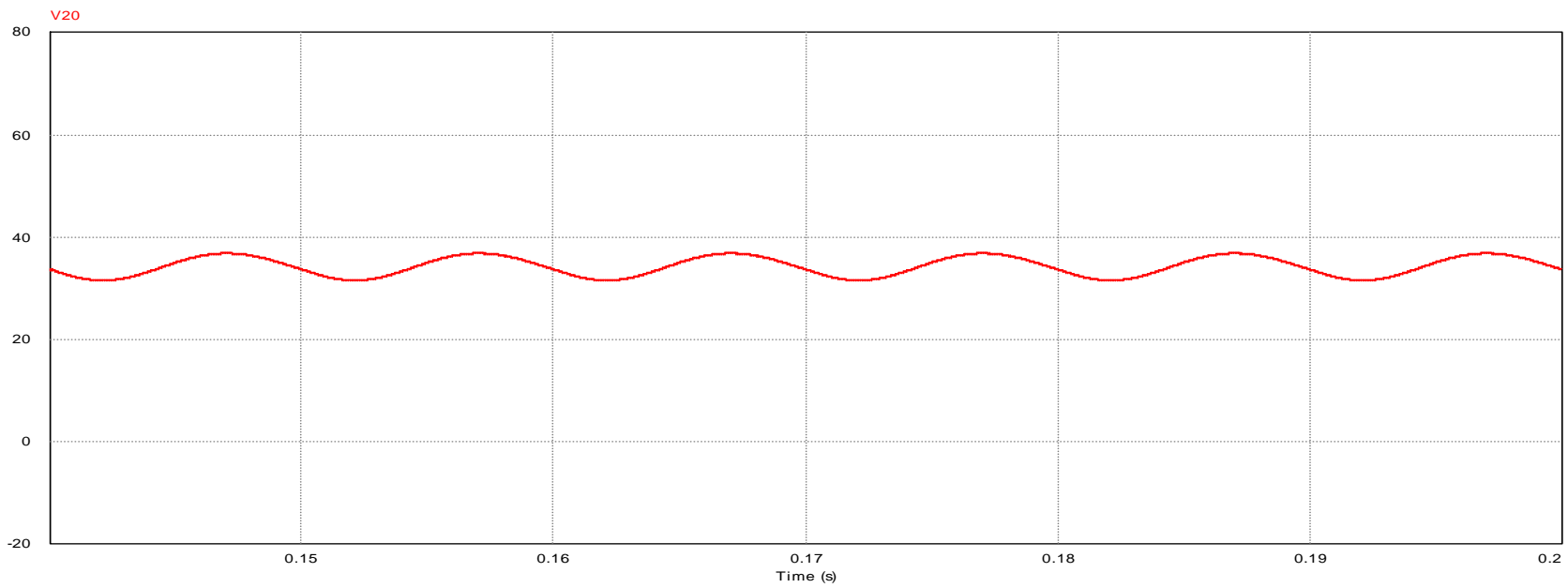

Figure 7. Output voltage: 36v (ripple: $5 v$ ).

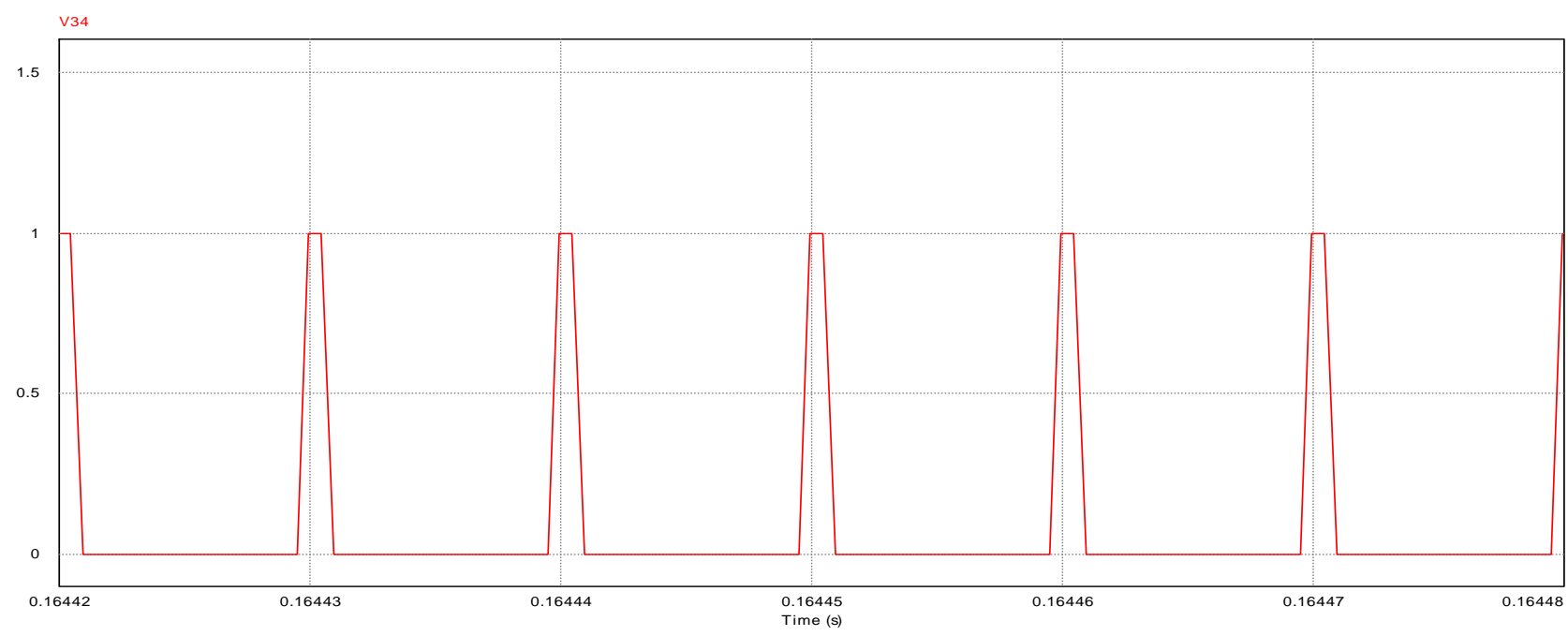

Figure 8. Constant duty cycle (0.15). 


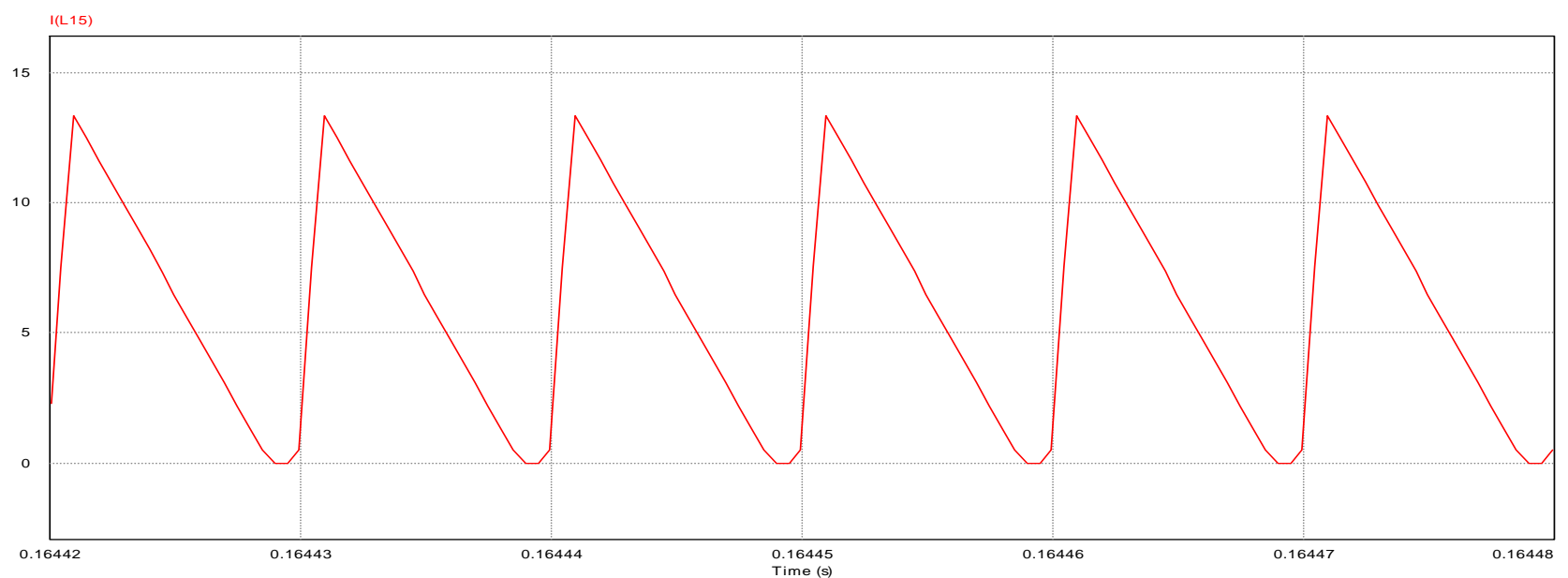

Figure 9. Output inductor current (L2 in Figure 1: DCM).

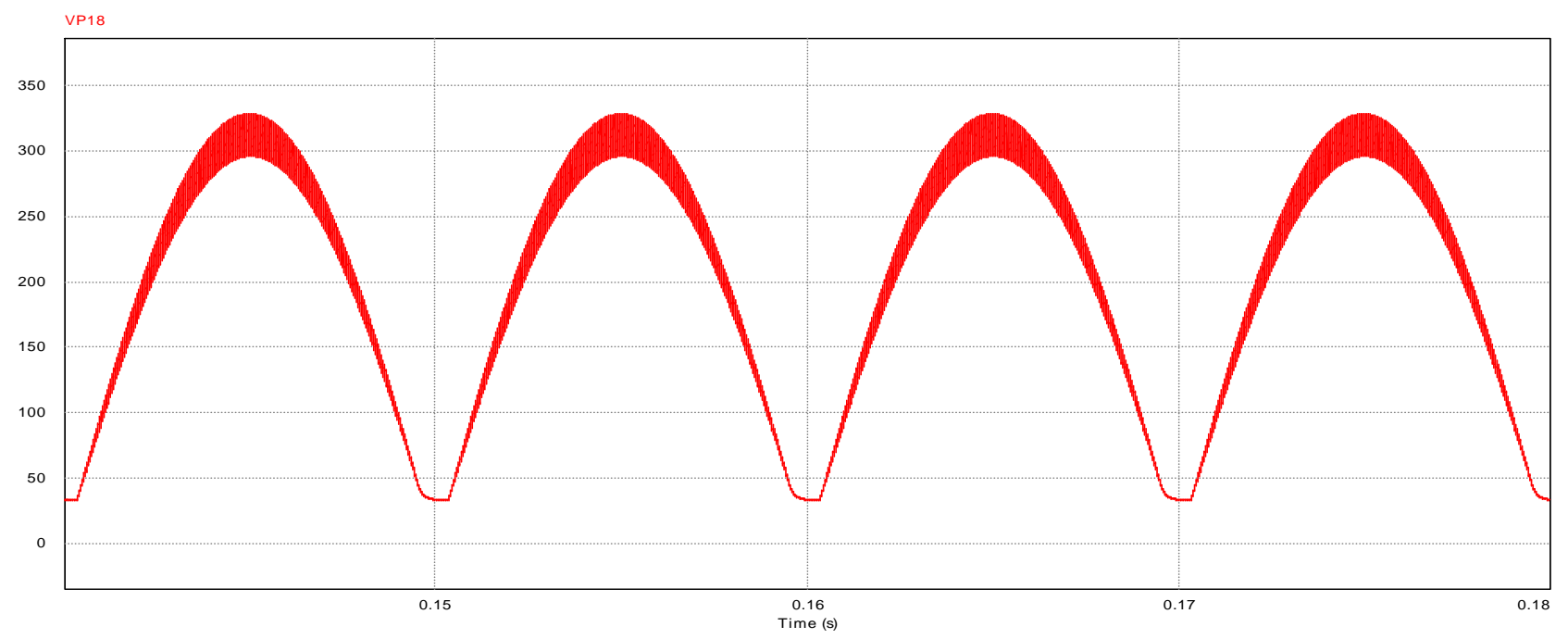

Figure 10. Input capacitor voltage (C1 in Figure 1: CCM).

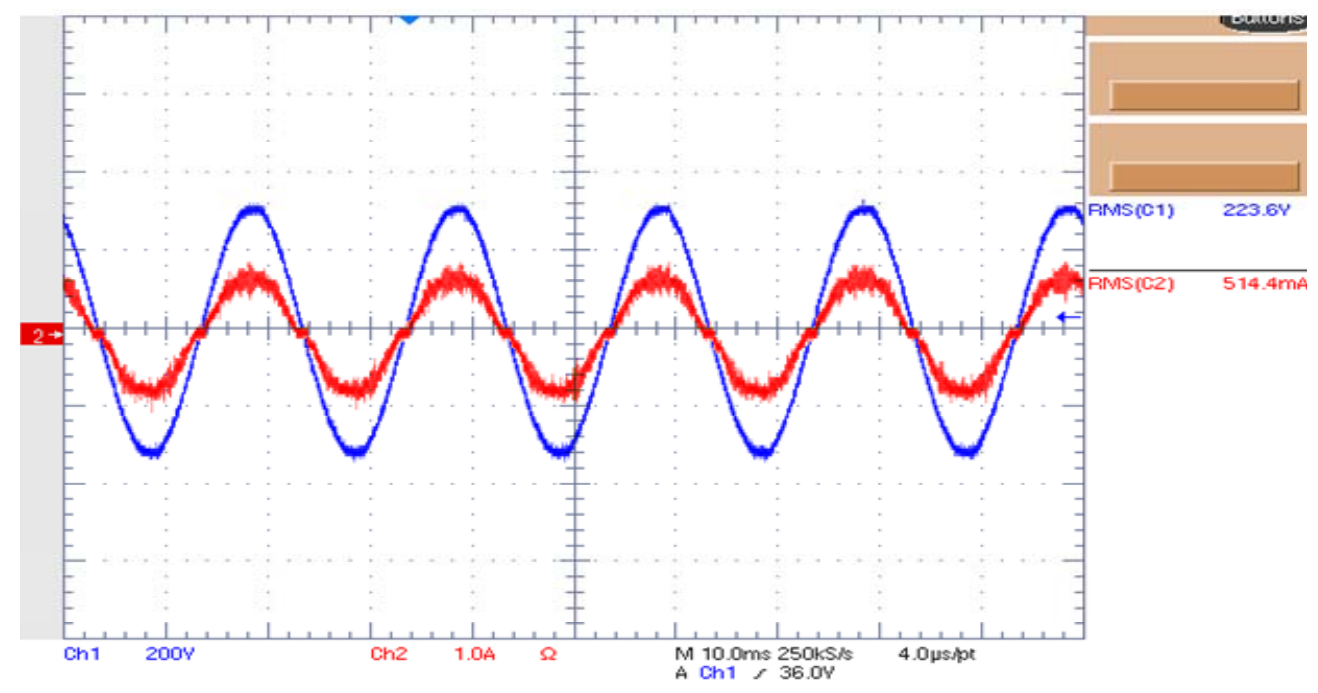

Figure 11. Input Voltage: 220vac Input Current: 0.54mA). 


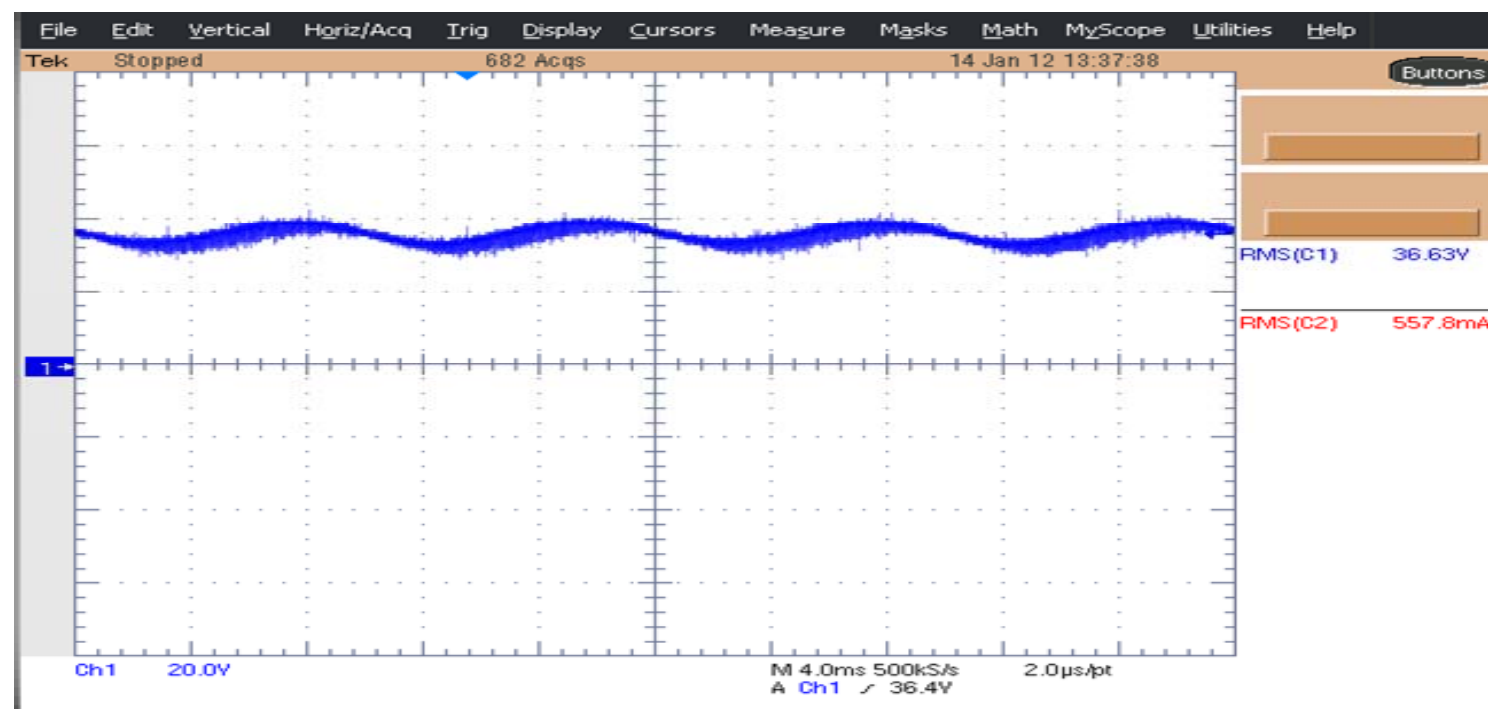

Figure 12. Output voltage: 36VDC (ripple: 5v).

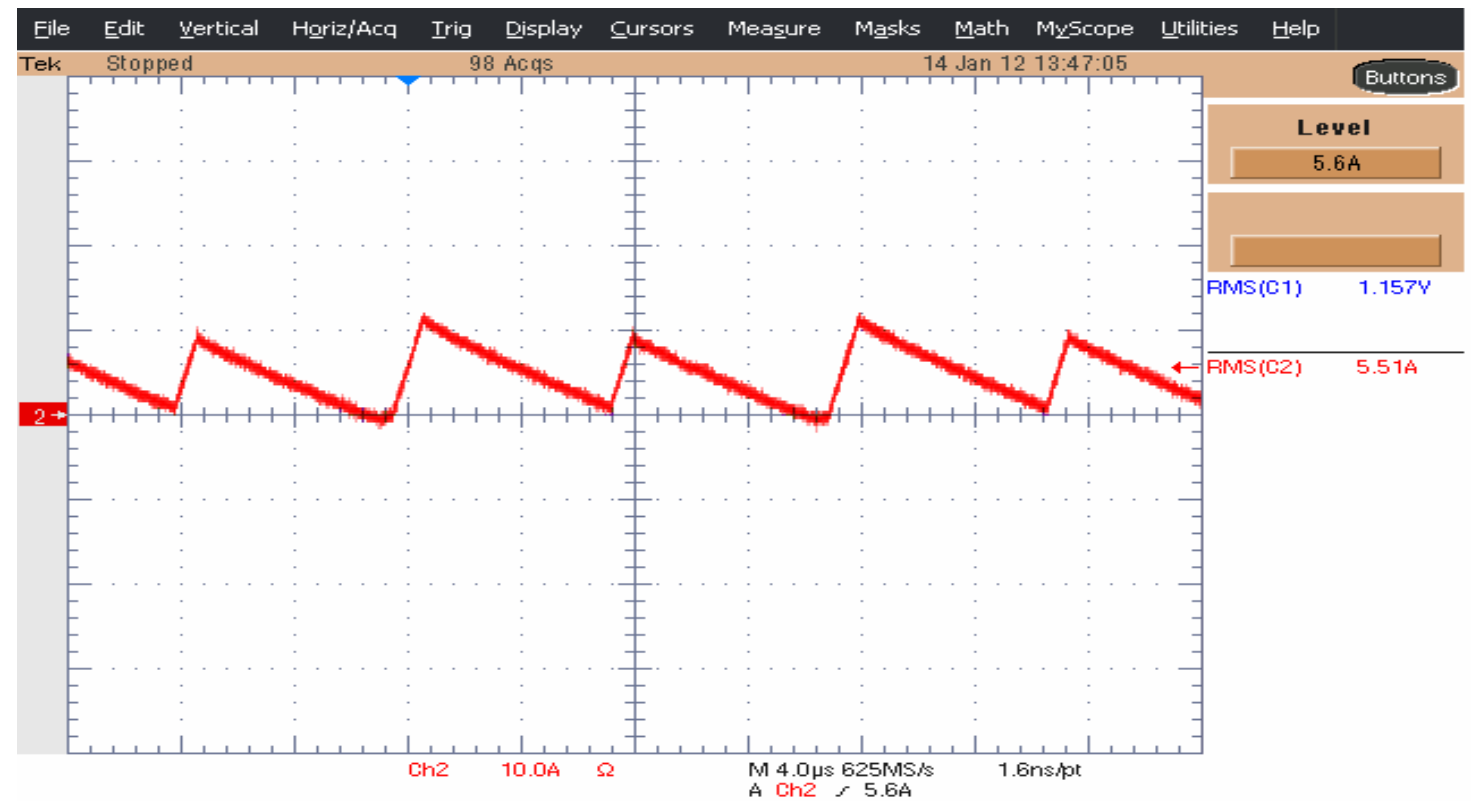

Figure 13. Output inductor current (L2 in Figure 1) DCM.

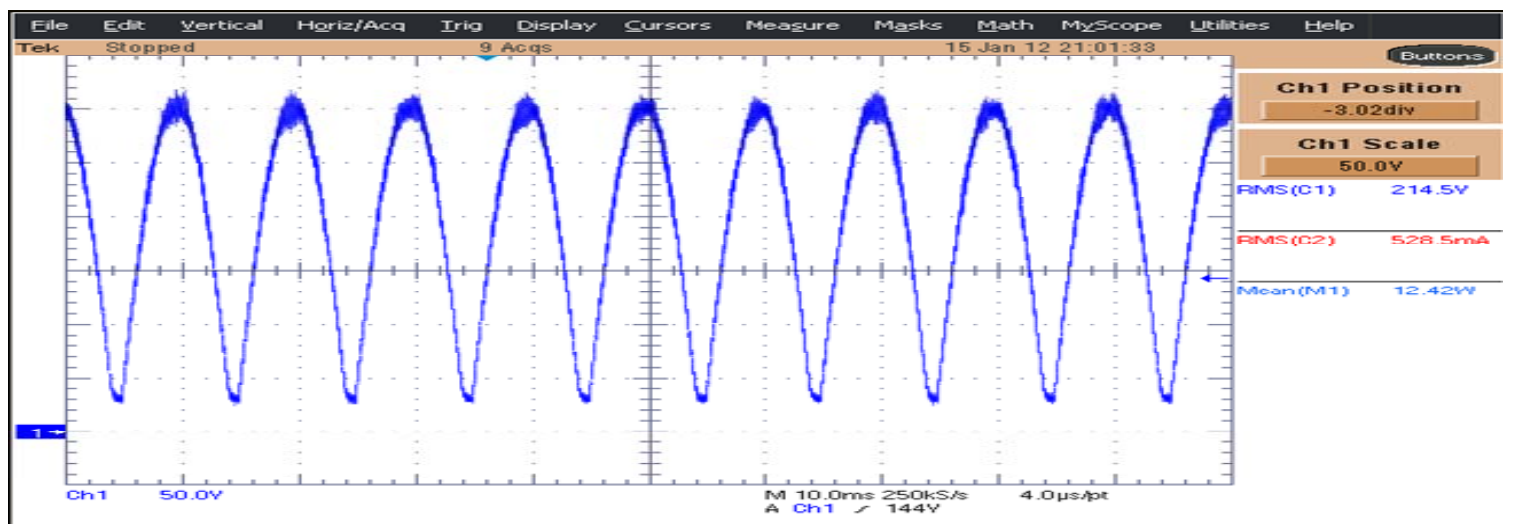

Figure 14. Input capacitor voltage (C1 in Figure 1) CCM. 


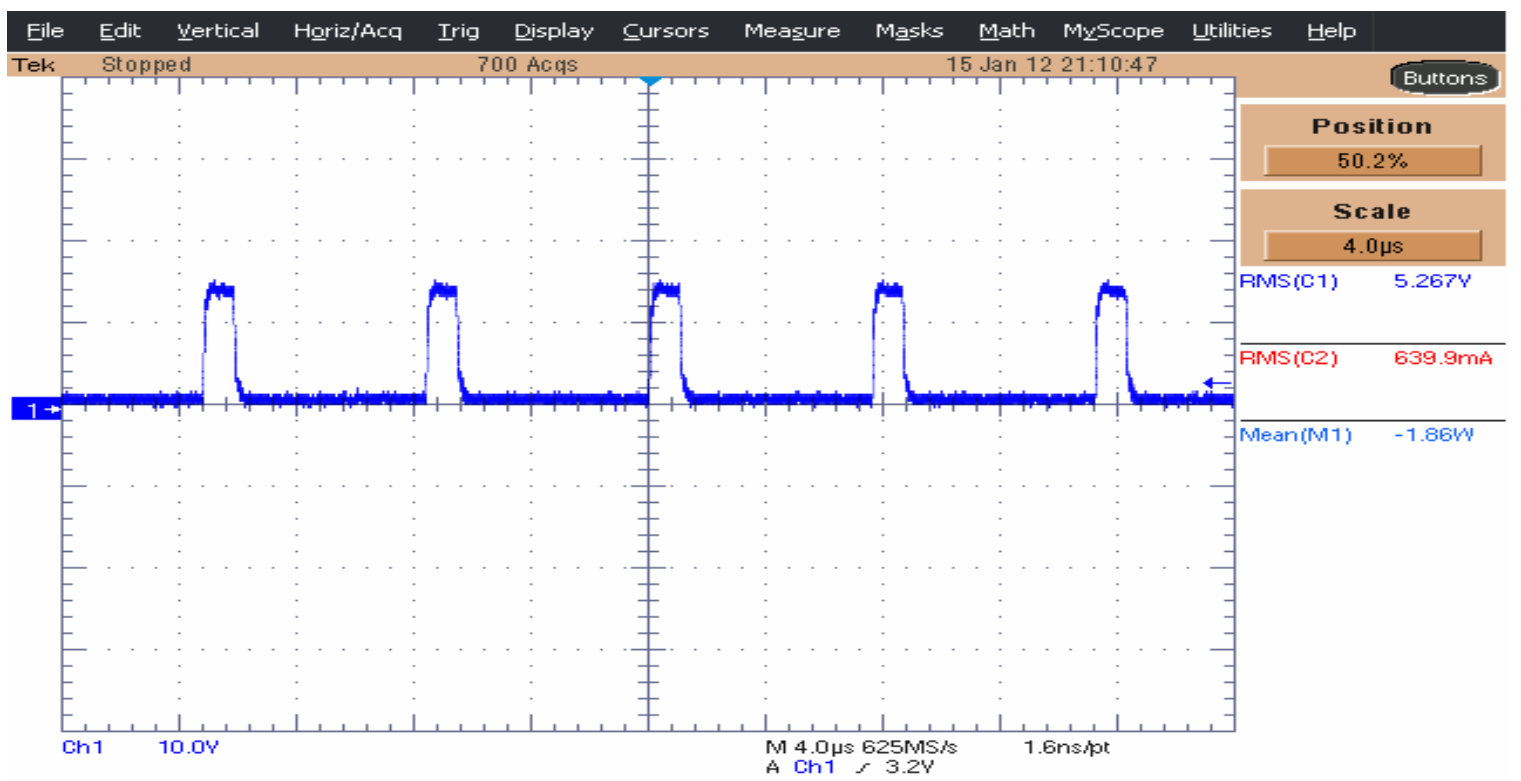

Figure 15. Constant duty cycle (0.15).

\section{Conclusions}

The Buck converter with LC input filter operating in DICM can gain a high power factor when the duty ratio maintain constant. Composed to the BOOST PFC converter, the Buck PFC converter can obtain an output voltage lower than the peak of the input voltage, which is suitable for the low DC voltage application. The detailed analysis presented in the paper suggested that the Buck converter may switch between DICM and DVCM if $\alpha / D<1$. When $k_{1}=\frac{2 L_{2}}{R T_{s}}$ is constant, the duty ratio is proportional to the conversation ratio $\alpha$. As the output voltage is constant, thus, the duty ratio is actually reversely proportional to the input voltage.

A $100 \mathrm{w}$ prototype has been built and the results verified the theoretical analysis in this paper

\section{Nomenclature}

DICM Discontinuous Inductor Current Mode

DCVM Discontinuous Capacitor Voltage Mode

\section{REFERENCES}

[1] D. S. Chen and J.-S. Lai, "A Study of Power Correction Boost Converteroperating at CCM-DCM Mode," in Proc. IEEE Southeastcon, Vol. 93, pp. 6-13.

[2] W. Tang, Y. Jiang, G. C. Hua, F. C. Lee and I. Cohen, "Power Factor Correction with Flyback Converter Employing Charge Control in APEC '93 Rec., pp. 293-298

[3] V. Vlatkovic, D. Borojevic and F. C. Lee, "Input Filter Design for Power Factor Correction Circuits," in $I E$ CON'93 Rec., Vol. 2, pp. 954-958.

[4] E. X. Yang, Y. Jiang, G. C. Hua and F. C. Lee, "Isolated Boost Circuit for Power Factor Correction," in IEEE APEC '93 Rec., pp. 196-203.

[5] Y. S. Lee, "Modeling, Analysis, and Application of Buck Converters in Discontinuous-Input-Voltage Mode Operation," IEEE Trans. Ind. Electron., Vol. 12, No. 2, MARCH 1997.

[6] V. Grigore and J. Kyyra, "High Power Factor Rectifier Based on Buck Converter Operating in Discontinuous Capacitor Voltage Mode," in Proc. IEEE Appl. Power Electron. Conf. Expo., Mar. 1999, pp. 612-618.

CCVM Continuous Capacitor Voltage Mode CICM Continuous Inductor Voltage Mode [6] 